\title{
A NEW ADSORBENT FOR ARSENIC REMOVAL FROM WATER
}

\author{
MIHAELA CIOPEC ${ }^{1}$, IOSIF HULKA ${ }^{2}$, NARCIS DUȚEANU ${ }^{1}$, ADINA NEGREA ${ }^{1}$, OANA GRAD ${ }^{2}$, \\ PETRU NEGREA $^{1}$, VASILE MINZATU $^{1} \&$ CRISTINA ARDEAN ${ }^{1}$ \\ ${ }^{1}$ Faculty of Industrial Chemistry and Environmental Engineering, Polytechnic University Timisoara, Romania \\ ${ }^{2}$ Research Institute of Renewable Energy, Polytechnic University Timisoara, Romania
}

\begin{abstract}
Water represents an essential resource for earth life and for all-natural processes. It is well known that in all developing countries the underground water resource represents the main source of drinking water and its contamination with arsenic presents a real problem. Thus, we have developed a new adsorbent based on cellulose doped with crown ethers (dibenzo-18-crown-6) functionalized with iron ions and used for the removal of arsenic from water. Usage of such extractants involves only a small amount of crown ether indicating higher efficiency of produced material, and, in order to improve the adsorbent properties and selectivity for arsenic removal, the modified cellulose was functionalized with iron ions. The new obtained adsorbent material was characterized by using energy dispersive X-ray analysis, scanning electron microscopy and Fourier Transform Infrared Spectroscopy. In order to investigate the adsorbent properties for arsenic removal equilibrium, kinetic and thermodynamic studies were performed. Arsenic adsorption from water onto a new adsorbent was studied under different experimental conditions such as reaction times, initial arsenic concentration and temperature. Obtained results show that the new produce adsorbent has a higher efficiency for arsenic removal, leading to

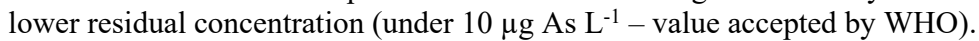

Keywords: arsenic, crown ethers, iron ions, water, adsorption.

\section{INTRODUCTION}

In accordance with principle of sustainable development a new and efficient material for arsenic removal from underground waters is presented in this paper. Major objective of present paper is to produce and test a new material with efficient properties for arsenic removal from underground waters. In order to achieve this, new chemically modified materials have been obtained and tested by functionalization with crown ethers and iron ions. Water represents an essential element for entire earth life and for all-natural processes. Our existence and our economic activities are very dependent on this precious resource. Especially into the developing countries main resource of drinkable water is represented by underground water so, their contamination with arsenic represent a major problem which must be solved [1]-[3]. Arsenic represent an element which can reach and contaminate water resources from a variety of anthropogenic and natural sources. Chronic exposure of humans at inorganic arsenic increases the risk of cancer. Studies showed that the arsenic inhalation can be associated with the increases of number of patients presenting lung cancer. Moreover, arsenic ingestion was associated with skin, bladder, liver and lung cancer. Because of its toxicity, the arsenic content in drinking water over maximum admitted level by the World Health Organization $\left(10 \mu \mathrm{g}\right.$ As $\left.\mathrm{L}^{-1}\right)$ has a negative impact on the human health [1]-[8]. Valence of arsenic inorganic species depends on the redox conditions and $\mathrm{pH}$ of the underground waters. In aqueous solutions at $\mathrm{pH}$ between 6 and $9 \mathrm{As}(\mathrm{V})$ can be found in form of four species: $\mathrm{H}_{3} \mathrm{AsO}_{4}, \mathrm{H}_{2} \mathrm{AsO}_{4}{ }^{-}, \mathrm{HAsO}_{4}{ }^{2-}, \mathrm{AsO}_{4}{ }^{3-}$, and $\mathrm{As}(\mathrm{III})$ species appear at $\mathrm{pH}=9$ as $\mathrm{H}_{3} \mathrm{AsO}_{3}, \mathrm{H}_{2} \mathrm{AsO}_{3}{ }^{-}, \mathrm{HAsO}_{3}{ }^{2-}, \mathrm{AsO}_{3}$ [4]-[6], [9], [10]. Therefore, to reduce the negative impact of arsenic towards human health is necessary to develop new and efficient technologies for its removal [3]. Conventional methods used for arsenic removal from aqueous solutions are 
precipitation, coagulation and filtration, inverse osmosis, ion exchange and adsorption. From all these methods, adsorption represent the most eloquent one, both form the efficiency of arsenic removal point of view and for the economical point of view [1]-[12]. In past years, it has been urgently necessary to obtain advanced composite materials with applications into the field of selective recovery and separation of metals and non-metals ions. Adsorption process efficiency can be improved by developing new methods to produce composite materials by chemical modification of inorganic and organic solid supports, through functionalization with different extractants. Currently, the used method for advanced adsorbent material production are: wet method (diluted extractant dissolved in different solvents is placed in contact with the solid support, being absorbed by the support), dry method (extractant is diluted in proper solvent is placed in contact with the support followed by slow evaporation of the solvent under vacuum), modifier addition (represent a hybrid between dry and wet methods), and the column dynamic method which present the advantage of the short time of functionalization correlated with increased efficiency of the adsorption process [13]-[24].

In order to apply these methods, the extractants should be liquid or be kept in liquid form by adding a proper solvent; extractant and solvent must have a minimum solubility, the support must be prepared for impregnation and the functionalization method does not have to change the extractant or support properties [13], [18], [25]. In last decade as support were used macroporous polymeric resins (Amberlite XAD resins) with a right three-dimensional structure appropriate to incorporate higher quantities of extractants due to proper specific surface area. In addition, they present great mechanical resistance and low solvent swelling time during functionalization process [25]. According to the specialty literature for the arsenic removal using Amberlite class polymers it is necessary to functionalize the used polymeric support through chemical synthesis, which leads at increase of the price of obtained material [26]. Other types of adsorbent materials used in arsenic removal process through adsorption are activated alumina, active carbon, copper-zinc granules, iron hydroxide granules, iron, aluminium, manganese oxides, etc. All these materials can be used as adsorption media as they are, or they can be impregnated on various supports such as silicates, ceramic materials, cellulose, etc. [27]-[29]. Such modified materials point out great adsorption capacities ( $>100 \mathrm{mg}$ As per each gram of material), but such materials cannot be used for removal of trace arsenic from underground waters (under $100 \mu \mathrm{g}$ per litter, case of waters form south-west of Romania due to the natural fond) [30]. In order to solve this stringent item, it is really important to develop new materials with efficient adsorbent properties.

Adsorbent properties of solid supports can be improved by chemical modification using functionalization method with different extractants. The main extractants used in the specialty literature are: organophosphoric acid extractants (di (2-etylhexyl) phosphoric acid - DEHPA, di (2-etylhexyl) ditiophosphoric acid - DEHTPA, 2-etylhexyl phosphoric acid mono - 2-etylhexil ester (HEHEHP), di (2, 4, 4-trimetyl-pentyl) phosphoric acid DTMPPA), neutral organophosphoric extractants (three - n-butyl phosphate - TBP, three n-octyl phosphine oxide - TOPO), mixture of organophosphoric acid extractants, bifunctional organophosphoric basic extractants, etc. [13], [15], [17], [18], [25].

Based on data presented onto the specialty literature is well known that the crown ethers can be successfully used for metal ions removal because they allowed the complexation and embedding of metallic ions inside or at their surface.

For the trace arsenic removal through adsorption is important that the adsorbent materials present good adsorbent properties, which can be obtained through chemical modification [31]. Based on that, the main objective was to obtain new materials with improved adsorbent 
properties by functionalization of solid supports using crown ethers as extractants, followed by loading with iron. The original aspect of the paper consists in the fact that literature is not presenting studies regarding the chemical modification of cellulose through functionalization with crown ethers and loaded with iron ions in the view of arsenic removal from waters. Even if the crown ethers are expensive reagents, the proposed method for their usage imply only small quantities, this way combining the advantage of crown ethers usage with the properties of solid supports. Obtained materials presents therefore high adsorbent performance at affordable price, moreover obtained materials are addressed to some niche applications such as arsenic removal from underground waters to achieve the WHO requirements.

\section{MATERIALS AND METHODS}

In order to obtain new adsorbent materials by chemical modification of solid support were used: as support cellulose (AVICEL 101, microcrystalline, powder, Sigma-Aldrich, Merck) with a particle size of $\sim 50 \mu \mathrm{m}$, as extractant Di-benzo 18 crown 6 (DB18C6) (purity, 98\%, Sigma-Aldrich, Merck), and iron chloride purchased from Sigma-Aldrich.

\subsection{Functionalization of polymers}

To obtain the modified adsorbent material, $0.1 \mathrm{~g}$ of Di-benzo 18 crown 6 (DB18C6) were accurately weighed and dissolved in $25 \mathrm{~mL}$ acetone $(99.9 \%$ SC ECO-MOLD Invest SRL, Romania). The obtained extractant solution is added over $5 \mathrm{~g}$ of support-cellulose with a particle size of $\sim 50 \mu \mathrm{m}$. The SIR dry method is used to functionalization the support. Thus, the extractant and the support remain in contact for 24 hours, after which it is filtered and dried in oven at $50^{\circ} \mathrm{C}$ for 24 hours. To load the material with iron ions $25 \mathrm{~mL}$ of $\mathrm{FeCl}_{3}$ solution with concentration of $100 \mathrm{mgL}^{-1}$ were added to the material, left in contact for 24 hours, then filtered and dried in the oven for 24 hours.

\subsection{Characterization of the functionalized polymers}

The materials obtained were characterized by X-ray dispersion (EDX) using a FEI Quanta FEG 250 instrument and Fourier Transformed Infrared Spectroscopy (FTIR) using a Bruker Platinum ATR-QL Diamond instrument in the range of $4000-400 \mathrm{~cm}^{-1}$.

\subsection{Sorption studies}

In order to determine optimum conditions for the arsenic adsorption process were carried out experiments regarding contact time, initial concentration of $\mathrm{As}(\mathrm{V})$ and temperature.

The experiments were carried out in a Julabo SW23 thermostatic and shaking water bath with a stirring speed of $200 \mathrm{rpm}$.

To establish the influence of contact time and temperature on the adsorption capacity of the functionalized material $0.1 \mathrm{~g}$ of material was mixed with $25 \mathrm{~mL} \mathrm{As}(\mathrm{V})$ solution with concentration of $50 \mu \mathrm{gL}^{-1}$. Samples were shaken for different time periods $(0.5,1,2,3,4,5$, $6,7,8$ hours) in a thermostatic bath at different temperatures $(298 \mathrm{~K}, 308 \mathrm{~K}$ and $318 \mathrm{~K})$ with a stirring speed of $200 \mathrm{rpm}$. After that all samples were filtered and the filtrate was analysed to evaluate the arsenic residual concentration using an Inductively coupled plasma mass spectrometer-ICP-MS Bruker Aurora M90 type.

In order to establish the effect of the initial concentration of $\mathrm{As}(\mathrm{V})$ on the adsorption capacity of materials, different concentrations of As(V) solutions (10, 25, 50, 75, 100, 150, 175 and $200 \mu \mathrm{gL}^{-1}$ ) were prepared. Adsorption processes were carried out at $\mathrm{pH} 7$, for a contact time of 4 hours at $298 \mathrm{~K}$. 


\section{RESULTS AND DISCUSSION}

\subsection{Characterization of the doped materials}

\subsubsection{X-ray energy dispersive spectroscopy}

Cellulose functionalized with DB18C6 and loaded with iron ions was characterized by using X-ray dispersion (EDX) technique. Obtained data are represented in Fig. 1. From the EDX spectra, can observe the presence of specific peaks of the elements from chemical structure of cellulose, crown ether namely $\mathrm{C}$ and $\mathrm{O}$ and iron.

\subsubsection{Fourier transform infrared spectroscopy}

The use of FTIR spectroscopy is used to identify chemical groups and for quantitative analysis of different samples. The FT-IR spectra for the studied material - cellulose functionalized with DB18C6 and iron are shown in Fig. 2.

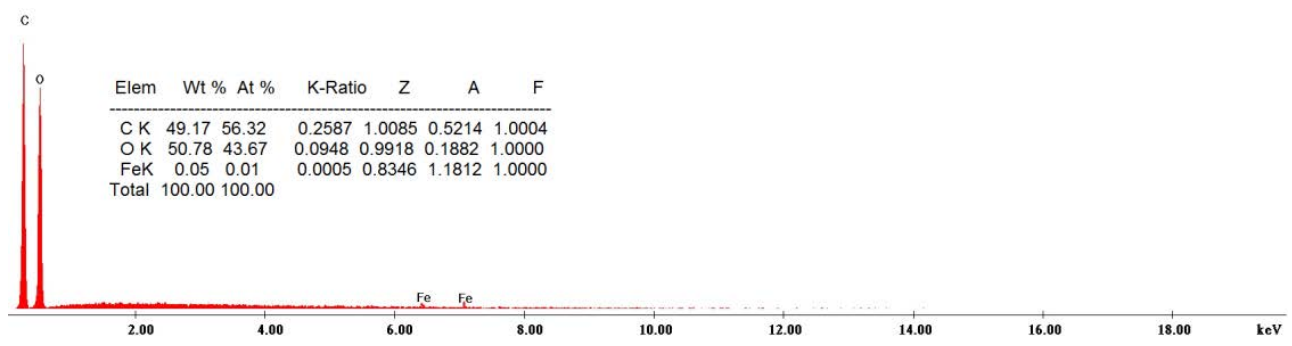

Figure 1: EDX spectra of materials obtained by functionalized cellulose with crown etherDB18C6 and iron doped.

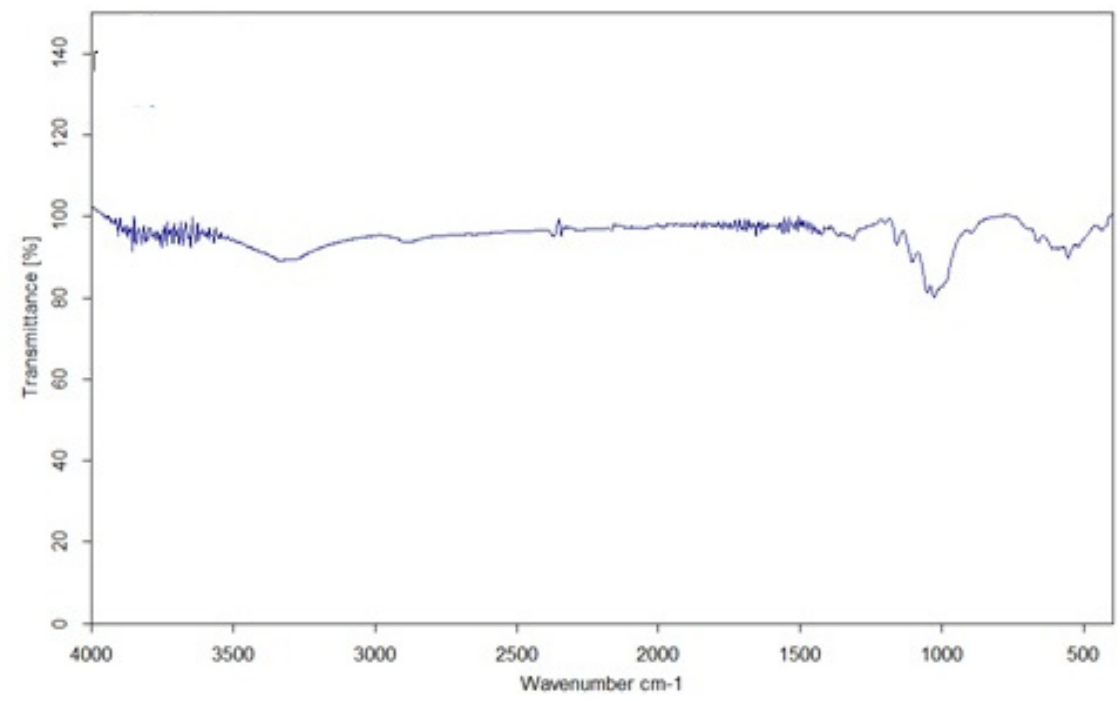

Figure 2: IR spectra of materials obtained by functionalized cellulose with crown etherDB18C6 and iron doped. 
From FTIR spectra (Fig. 2) obtained for cellulose functionalized with DB18C6 and loaded with iron ions were identified the bands specific for cellulose groups, in the range of 3200$3400 \mathrm{~cm}^{-1}$ associated with the stretching vibrations of O-H bonds [32]. Simultaneously was identified a band located around $1600 \mathrm{~cm}^{-1}$ which are characteristic for stretching vibrations water specific $\mathrm{O}-\mathrm{H}$ bonds. The bands located at 1720 and $1600 \mathrm{~cm}^{-1}$ are assigned to aromatic $\mathrm{C}=\mathrm{C}$ bond stretching vibrations [33]. Bands characteristic of DB18C6 extractant appear in the range $1550-500 \mathrm{~cm}^{-1}$, the most intense are located at $1000 \mathrm{~cm}^{-1}$ and $550 \mathrm{~cm}^{-1}$ [34].

Thus, dibenzo-18-crown-6-crown ether specific vibrations bands can be observed around $1000 \mathrm{~cm}^{-1}$ and $1100 \mathrm{~cm}^{-1}$ that can be attributed to Calphatic-O-Caromatic respectively Calphatic-O-Calphatic bonds [31]. At the same time, iron surface loading is evidenced by the presence of $1037 \mathrm{~cm}^{-1}$ of some peaks characteristic of the $\mathrm{Fe}-\mathrm{OH}$ bonds [30].

\subsection{Sorption studies results}

\subsubsection{The effect of contact time, temperature and sorption kinetics studies}

The effect of contact time on the adsorption of $\mathrm{As}(\mathrm{V})$ on the obtained functionalized material was studied as was previously described. Obtained experimental data are showed in Fig. 3. For this study, contact time was varied in the range between $0.5-8$ hours, and temperature in the range $298-318 \mathrm{~K}$. From data depicted in Fig. 3 can observe that the adsorption capacity increases with the increase of contact time, and the equilibrium is reached after about 4 hours for all used temperatures. At the same time, it is observed that with the temperature increase, the adsorption capacity of the material is not significantly affected. In order to study the $\mathrm{As}(\mathrm{V})$ adsorption mechanism the experimental data were modelled using pseudo-first-order and pseudo-second order kinetic models.

Fig. 4 depicts the pseudo-first-order and pseudo-second order kinetic model's plots obtained at temperatures used during adsorption experiments (298, 308 and $318 \mathrm{~K})$.

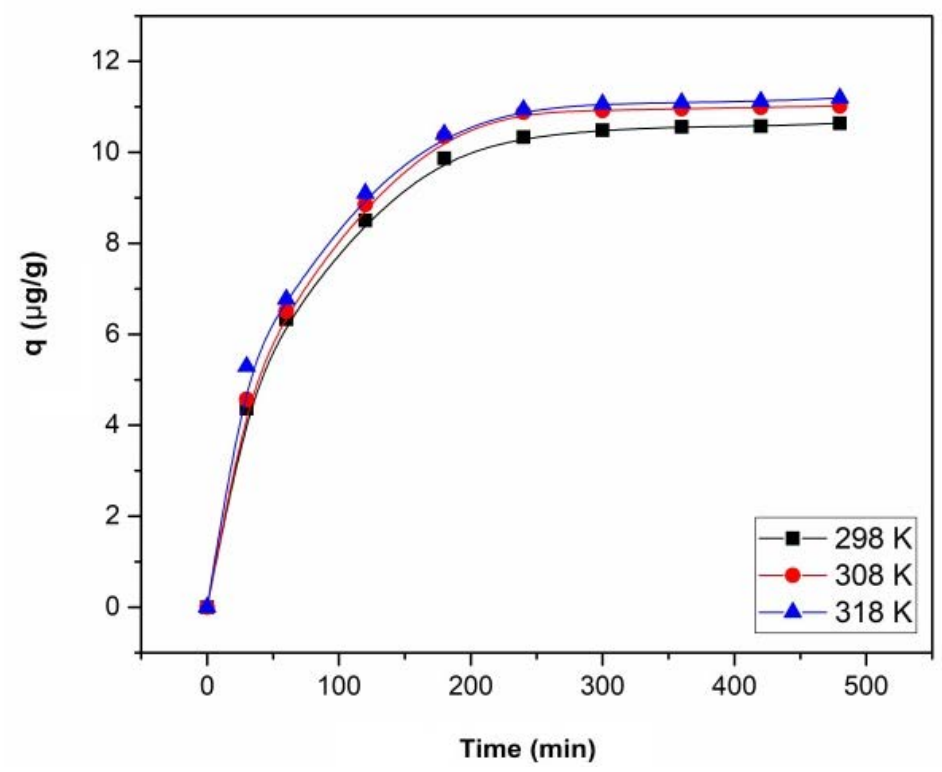

Figure 3: Effect of contact time on the adsorption capacity of the studied material. 


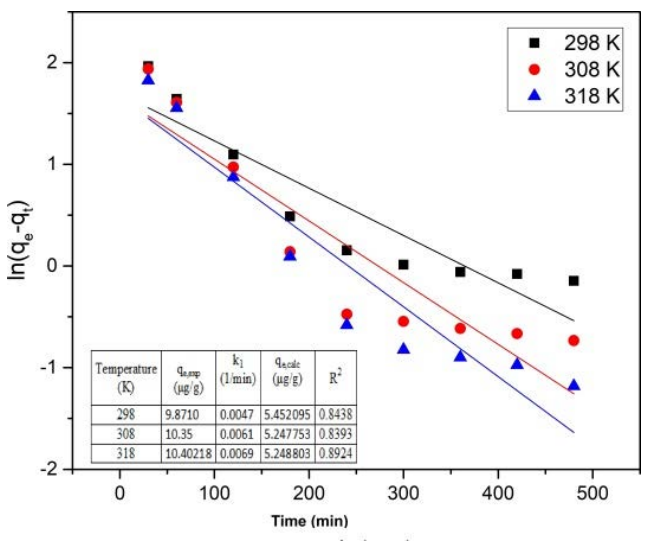

(a)

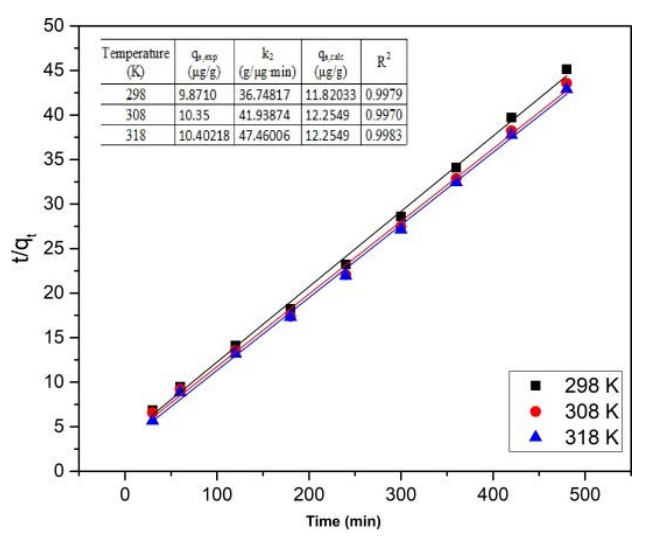

(b)

Figure 4: Pseudo-first-order and pseudo-second-order plots for As(V) adsorption onto the material. (a) Pseudo-first-order kinetic model; (b) Pseudo-second-order kinetic model.

Kinetic parameters for $\mathrm{As}(\mathrm{V})$ sorption onto studied material at three different temperatures obtained from used kinetic models are presented in Fig. 4. The value of constant $\mathrm{k}_{1}$ for the pseudo-first-order model was calculated using the slope of the linear graphical representation of $\ln$ (qe-qt) function of time.

Similarly, the constant k was determined for pseudo-second-order model, from the slope of the linear graphical representation of the $\mathrm{t} / \mathrm{qt}$ as function of time. If the correlation coefficient $\mathrm{R}^{2}$ is closer to 1 , the adsorption process presents a better linearization for one of the two kinetic models presented. Thus, from the experimental data presented in the tables from Fig. 4, it is observed that pseudo-second-order model is better describing the arsenic adsorption onto the studied material, because the obtained correlation coefficient $\mathrm{R}^{2}$ is in the range 0.9970-0.9983 depending on the temperature and is higher than that found for the pseudo-first-order model $\left(\mathrm{R}^{2}=0.8438-0.8924\right)$. Due to the fact that adsorption kinetics was better described by the pseudo-second-order kinetic model compared to the pseudo-firstorder model suggesting that the $\mathrm{As}(\mathrm{V})$ removal process correspond to a chemisorption mechanism.

In order to establish the $\mathrm{As}(\mathrm{V})$ behaviour on the surface of the adsorbent material during the adsorption process, the experimental data obtained were modelled according to Langmuir, Freundlich and Sips isotherms (depicted in Fig. 5) generally used to describe the adsorption processes. The correlation coefficient $\mathrm{R}^{2}$ was calculated to establish which adsorption isotherm describes better the adsorption process of $\mathrm{As}(\mathrm{V})$. Inset of figures are presented the parameters obtained for each used isotherm. The highest value of the correlation coefficient $\mathrm{R}^{2}$ obtained when the experimental data were modelled using Langmuir isotherm $\left(\mathrm{R}^{2}=0.91685\right)$ versus the Freundlich isotherm $\left(\mathrm{R}^{2}=0.79081\right)$ allows us to consider that the Langmuir isotherm describes better the $\operatorname{As}(\mathrm{V})$ adsorption process onto the chemically modified material. But because the value of the correlation coefficient $\mathrm{R}^{2}$ for Sips isotherm is much closer to $1\left(\mathrm{R}^{2}=0.99726\right)$, can conclude that the Sips model best describes the adsorption process.

It is also observed that the value of maximum adsorption capacity evaluated based on Sips

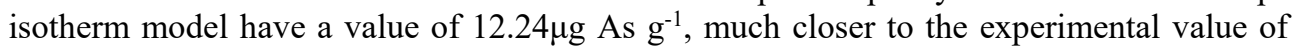




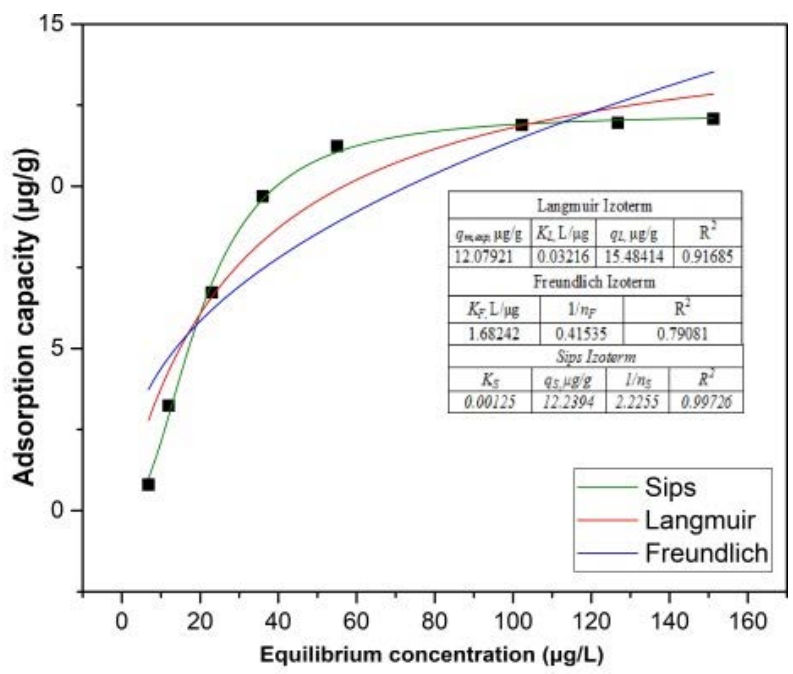

Figure 5: Adsorption isotherm of $\mathrm{As}(\mathrm{V})$ onto material.

$12.079 \mu \mathrm{g} \mathrm{As} \mathrm{g}^{-1}$. Based on that can conclude that the adsorption process of $\mathrm{As}(\mathrm{V})$ on the obtained material is mono-layer adsorption on to the heterogeneous surface. The adsorption mechanism is controlled by chemisorption processes as a result of strong chelation between $\mathrm{As}(\mathrm{V})$ and $\mathrm{OH}^{-}$groups or $\mathrm{Fe}(\mathrm{III})$ ions present on the functionalized material surface. The value of the coefficient $\mathrm{n}_{\mathrm{s}}<2$ can confirm that it is possible that adsorption process is produced by moving the $\mathrm{As}(\mathrm{V})$ ions from the aqueous phase to the material surface.

\subsubsection{Thermodynamics of the adsorption}

In order to investigate the spontaneity and thermal properties of the adsorption process, the effect of the temperature on the adsorption process of $\mathrm{As}(\mathrm{V})$ was investigated by varying the temperature in the range $298-318 \mathrm{~K}$. Also, in order to determine if the adsorption process of $\mathrm{As}(\mathrm{V})$ ions onto the studied material corresponds to a physical sorption or to a chemical sorption, the activation energy was calculated using the well-known Arrhenius equation; obtained Arrhenius plot is present in Fig. 6.

Thermodynamic parameters associated with $\mathrm{As}(\mathrm{V})$ adsorption process on the functionalized material are present in inset table from Fig. 6.

Correlation coefficient $\mathrm{R}^{2}$ has a value equal with 0.9985 . The positive value of enthalpy $\Delta \mathrm{H}^{\circ}$ demonstrates that the energy necessary for the adsorption process is the energy used to put in contact $\mathrm{As}(\mathrm{V})$ ions with the surface of the adsorbent material. The negative value obtained for free Gibbs energy suggest that the adsorption process of $\mathrm{As}(\mathrm{V})$ on the functionalized material is a spontaneous and natural process. These values become more negative with the increase of the temperature, which can be attributed to effective growth of the contact surface of the adsorbent material and the $A s(V)$ ions. The positive value of entropy $\left(\Delta \mathrm{S}^{\circ}\right)$ suggest that adsorption increases at material/solution interface and the degree of particles clutter increases with increasing temperature, which can be attributed to some changes at the surface of the material. Thus, the adsorption of $\mathrm{As}(\mathrm{V})$ on the material surface is an endothermic and spontaneous process. Also, the value of activation energy has a value of $10.07 \mathrm{~kJ} / \mathrm{mol}^{-1}$ suggesting that the adsorption of $\mathrm{As}(\mathrm{V})$ onto the studied material is a chemical adsorption. 


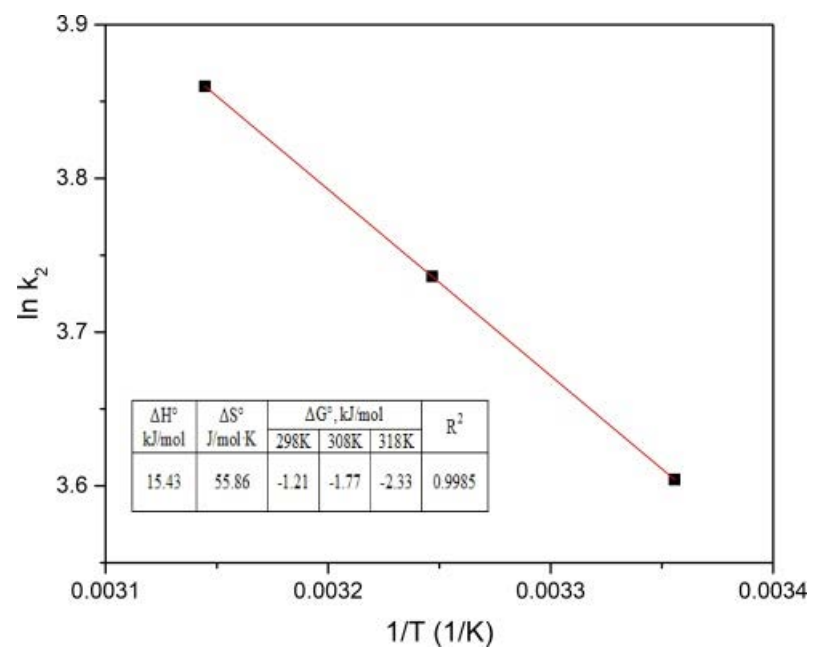

Figure 6: Arrhenius plot of $\mathrm{As}(\mathrm{V})$ adsorption onto studied material.

\section{CONCLUSIONS}

The present research was aimed to produce a new material with adsorbent properties based on cellulose support functionalized with crown ether Di-benzo 18 crown 6 (DB18C6) and loaded with iron ions used for $\mathrm{As}(\mathrm{V})$ removal from aqueous solutions. The material was physical-chemical characterized by X-ray dispersion (EDX) and FTIR spectroscopy to highlight the modification of the cellulose surface by doping with crown ether and iron ions loading the obtained material. The mechanism of the adsorption process of $\mathrm{As}(\mathrm{V})$ on the material was established, performing kinetic, thermodynamic and equilibrium studies. The results indicate that the adsorption process takes place at the surface of the material, being a spontaneous, endothermic, natural process, and the nature of the interactions between the metal ions and the surface of the material may be chemical bonds. The adsorption kinetics was better described by the pseudo-second-order kinetic model compared to the pseudo-firstorder model and the isotherm which best corresponds to the process is the Sips isotherm.

\section{ACKNOWLEDGEMENT}

This work was supported by research grants PCD-TC-2017.

\section{REFERENCES}

[1] WHO, Arsenic in drinking water. World Health Organization, 2011, Online. www.who.int/water_sanitation_health/dwq/chemicals/arsenic.pdf. Accessed on: 30 Nov. 2017.

[2] Ramesh, A., Hasegawa, H., Maki, T. \& Ueda, K., Adsorption of inorganic and organic arsenic from aqueous solutions by polymeric Al/Fe modified montmorillonite. Sep. Purif. Technol., 56, pp. 90-100, 2007.

[3] Guo, H., Stuben, D. \& Berner, Z., Arsenic removal from water using natural iron mineral quartz sand columns. Sci. Total Environ., 377, pp. 142-151, 2007.

[4] Kundu, S. \& Gupta, A.K., Adsorptive removal of As(III) from aqueous solution using iron oxide coated cement (IOCC): Evaluation of kinetic, equilibrium and thermodynamic models. Sep. Purif. Technol., 51, pp. 165-172, 2006. 
[5] Borah, D., Satokawa, S., Kato, S. \& Kojima, T., Surface-modified carbon black for As(V) removal. J. Colloid Interface Sci., 319, pp. 53-62, 2008.

[6] Borah, D., Satokawa, S., Kato, S. \& Kojima, T., Sorption of As(V) from aqueous solution using acid modified carbon black. J. Hazard. Mater., 162, pp. 1269-1277, 2009.

[7] Negrea, A., Lupa, L., Ciopec, M., Lazau, R., Muntean, C. \& Negrea, P., Adsorption of As(III) ions onto iron containing waste sludge. Adsorpt. Sci. Technol., 28, pp. 467484, 2010.

[8] Goswami, R., Deb, P., Thakur, R., Sarma, K.P. \& Bsumalick, A., Removal of As(III) from aqueous solution using functionalized ultrafine iron oxide nanoparticles. Sep. Sci. Technol., 46, pp. 1017-1022, 2011.

[9] Gupta, K. \& Ghosh, U.C., Arsenic removal using hydrous nanostructure iron(III) titanium(IV) binary mixed oxide from aqueous solution. J. Hazard. Mater., 161, pp. 884-892, 2009.

[10] Hlavay, J. \& Polyak, K., Determination of surface properties of iron hydroxide coated alumina adsorbent prepared from drinking water. J. Colloid Interface Sci., 284, pp. 71-77, 2005.

[11] Banerjee, K. et al., Kinetic and thermodynamic aspects of adsorption of arsenic onto granular ferric hydroxide (GFH). Water Res., 42, pp. 3371-3378, 2008.

[12] Oke, I.A., Olarinoye, N.O. \& Adewusi, S.R.A., Adsorption kinetics for arsenic removal from aqueous solutions by untreated powdered eggshell. Adsorption, 14(73), pp. 1-12, 2008.

[13] Juang, R.S., Preparation, properties and sorption behaviour of Impregnated resins containing acidic organophosphorus extractants. Proc. Natl. Sci. Counc. ROC(A), 23, pp. 353-364, 1999.

[14] Shao, W., Li, X., Cao, Q., Luo, F., Li, J. \& Du, Y., Adsorption of arsenate and arsenite anions from aqueous medium by using metal(III)-loaded Amberlite resins. Hydrometallurgy, 91, pp. 138-143, 2008.

[15] Zhu, X. \& Jyo, A., Removal of arsenic(V) by zirconium(IV)-loaded phosphoric acid chelating resin. Sep. Sci. Technol., 36(14), pp. 3175-3189, 2001.

[16] Saha, B., Gill, R.J., Bailey, D.G., Kabay, N. \& Arda, M., Sorption of Cr(VI) from aqueous solution by Amberlite XAD-7 resin impregnated with ALiquat 336. React. Funct. Polyp., 60, pp. 223-244, 2004.

[17] Belkhouche, N.E. \& Didi, M.A., Extraction of Bi(III) from nitrate medium by D2EHPA impregnated onto Amberlite XAD-1180. Hydrometallurgy, 103, pp. 60-67, 2010.

[18] Negrea, A. et al., Removal of As(V) by Fe(III) loaded XAD7 impregnated resin containing di(2-ethylhexyl) phosphoric acid (DEHPA): Equilibrium, Kinetic and Thermodynamic modelling studies. J. Chem. Eng. Data., 56, pp. 3830-3838, 2011.

[19] Ciopec, M., Negrea, A., Davidescu, C.M., Negrea, P., Muntean, C. \& Popa, A., Use of Di-(2-Ethylhexyl)-Phosphoric Acid (DEHPA) Impregnated XAD-8 Copolymer Resin for the Separation of Metal Ions from Water. Chem. Bull. "Politehnica" Univ. Timisoara, 55(69), pp. 127-131, 2010.

[20] Suzuki, T.M., Bomani, J.O., Matsunga, H. \& Yokoyama, T., Preparation of porous resin loaded with crystalline hydrous zirconium oxide and its application to the removal of arsenic. React. Funct. Polym., 43(1-2), pp. 165-172, 2000.

[21] Haron, M.J., Shiah, L.L. \& Wan Yunus, W.M.Z., Sorption of arsenic(V) by titanium oxide loaded poly(hydroxamic acid) resin. The Malaysian Journal of Analytica Sciences, 10, pp. 261-268, 2006. 
[22] Benamor, M., Bouariche, Z., Belaid, T. \& Draa, M.T., Kinetic studies on cadmium ions by Amberlite XAD7 impregnated resin containing di(2-ethylhexyl) phosphoric acid as extractant. Sep. Purif. Technol., 59, pp. 74-84, 2008.

[23] Mendoza, R.N., Medina, I.S., Vera, A. \& Rodriguez, M.A., Study of the sorption of Cr(III) with XAD-2 resin impregnated with di-(2,4,4-trimethylpentyl)phosphinic acid (Cyanex 272). Solvent Extr. Ion Exch., 18, pp. 319-343, 2000.

[24] Muraviev, D., Ghantous, L. \& Valiente, M., Stabilization of solvent impregnated resin capacities by different techniques. React. Funct. Polym., 38, pp. 259-268, 1998.

[25] Cortina, J.L. and Warshawsky, A., Solvent Extraction \& Ion Exchange, eds J.A. Marinsky \& Y. Marcus, Marcel Dekker: New York, 13, 1997.

[26] Suzuki, T.M., Bomani, J.O., Matsunga, H. \& Yokoyama, T., Preparation of porous resin loaded with crystalline hydrous zirconium oxide and its application to the removal of arsenic. React. Funct. Polym., 43(1-2), pp. 165-172, 2000.

[27] Guo, H., Stuben, D. \& Berner, Z., Absorbtion of arsenic(III) and arsenic(V) from groundwater using natural siderite as the absorbent. Colloid and Interface Science, 315, pp. 47-53, 2007.

[28] Zeng, L., A method preparing silica-containing iron(III) oxide adsorbents for arsenic removal. Water Research, 37, pp. 4351-4358, 2003.

[29] Streat, M., Hellgardt, K. \& Newton, N.L.R., Hydrous ferric oxide as an adsorbent in water treatment. Part 2. Adsorption studies. Process Safety and Environmental Protection, 86, pp. 11-20, 2008.

[30] Ciopec, M., Negrea, A., Lupa, L., Davidescu, C.M. \& Negrea, P., Studies regarding As(V) adsorption from Underground Water by Fe-XAD8-DEHPA Impregnated Resin. Equilibrium Sorption and Fixed-Bed Column Tests. Molecules, 19, pp. 1608216101, 2014.

[31] Negrea, A. et al., Phosphonium grafted styrene-diviniylbenzene resins impregnated with iron(III) and crown ethers for arsenic removal. Pure Apl. Chem., 86(11), pp. 1729-1740, 2014.

[32] Puziy, A.M., Poddubnaya, O.I., Martnez-Alonso, A., Suarez-Garcia, F. \& Tascon, J.M.D., Synthetic carbons activated with phosphoric acid I. Surface chemistry and ion binding properties. Carbon, 40, pp. 1493-1515, 2002.

[33] Hassan, H.S., Attallah, M.F. \& Yakout, S.M., Sorption characteristics of an economical sorbent material used for removal radioisotopes of cesium and europium. J. Radioanal. Nucl. Chem., 286, pp. 17-26, 2010.

[34] Gabor, A. et al., Magnesium silicate doped with environmentally friendly extractants used for rare earth elements adsorption. Desalinitation and Water Treatment, 63, pp. 124-134, 2017. 